\title{
A homossexualidade e a Perspectiva foucaultiana
}

\author{
Francis Madlener ${ }^{\star}$ \\ Nilson Fernandes Dinis ${ }^{\star \star}$
}

\begin{abstract}
Resumo
O dispositivo da sexualidade produziu prescrição de normas que interferem na constituição das identidades sexuais dos sujeitos, sejam eles/elas hetero ou homossexuais. Deve-se refletir de que forma esse processo ocorre e quais prejuizos pode trazer para uma experiência que poderia ser criadora de novas formas de relações. Assim Foucault questiona mesmo a luta dos movimentos homossexuais e seus referenciais identitários excludentes. Busca-se, com este trabalho, trazer uma reflexão acerca do dispositivo da sexualidade, sua influência nas relações homossexuais, bem como as possibilidades de superação dos atuais padrões sociais e sexuais na direção de novas estéticas da existência.
\end{abstract}

Palavras-chave: Sexualidade. Gênero. Homossexualidade.

\section{HoMOSEXUALITY AND FOUCAULT'S PERSPECTIVE}

\begin{abstract}
The sexuality device produced prescription of norms that interferes in the sexual identities construction of the fellows, as heterosexual or homosexual. It is necessary to think about how that process happened and what kind of damages can take to an experience which could create news forms of relationship. This way, Foucault discusses even the homosexual movements fight and their excluding identity references. This work aims to put some questions about the sexuality device, their influence on the homosexual relationships and to point to the possibilities of overcoming the social and sexual standards into new forms of existence.
\end{abstract}

Keywords: Sexuality. Gender. Homosexuality.

^ Mestre em Educação, professora substituta na Universidade Federal do Paraná e professora da Rede Municipal de Ensino/Curitiba.

E-mail: francis_mad@hotmail.com

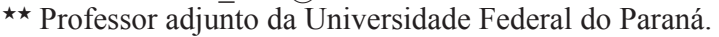

E-mail:ndinis@ufpr.br 
Antes de iniciar-se a discussão acerca da concepção foucaultiana de homossexualidade, faz-se necessário compreender as questões referentes ao que Foucault denominou "dispositivo da sexualidade". Para o autor, este seria o meio pelo qual a sexualidade é produzida e regida, bem como o sexo (ato sexual), disciplinado. Em suas palavras:

Através deste termo [dispositivo] tento demarcar [...] um conjunto decididamente heterogêneo que engloba discursos, instituições, organizações arquitetônicas, decisões regulamentares, leis, medidas administrativas, enunciados científicos, proposições filosóficas, morais, filantrópicas. Em suma, o dito e o não dito são os elementos do dispositivo. $\mathrm{O}$ dispositivo é a rede que se pode estabelecer entre estes termos (FOUCAULT, 1996, p. 244).

Assim, por dispositivo da sexualidade, entendem-se práticas discursivas e não discursivas, saberes e poderes que visam normatizar, controlar e estabelecer "verdades" a respeito do corpo e seus prazeres. O dispositivo é "um tipo de formação que, em um determinado momento histórico, teve como função principal responder a uma urgência" (FOUCAULT, 1996, p. 244), ou seja, em determinado momento histórico, a partir de contextos específicos, surgem discursos e práticas que visam responder às demandas sociais, políticas ou morais.

Este dispositivo, com suas verdades e valores morais, dita aquilo que deve ser praticado, interfere nas subjetividades e nas construções individuais referentes aos prazeres e ao corpo. Esta influência se dá em todos aqueles indivíduos que não se desprendem deste dispositivo, sejam eles heterossexuais ou homossexuais. Podese ainda acrescentar que a concepção de sexualidade que se adota segue um padrão fálico, em que o prazer sexual está intrinsecamente ligado ao ato sexual e principalmente à penetração, em ambos os casos de relações sexuais (homo ou heterossexuais).

O dispositivo da sexualidade tem o poder (e é sustentado por este mesmo poder) de tornar o sexo possuidor de uma verdade sobre o indivíduo, uma vez que por meio dele se pode alcançar as profundezas do ser:

Não obstante, a idéia de que se deve ter um verdadeiro sexo está longe de ser dissipada. Seja qual for a opinião dos biólogos a esse respeito, encontramos, pelo menos em estado difuso, não apenas na psiquiatria, psicanálise e psicologia, mas também na opinião pública, a idéia de que entre sexo e verdade existem relações complexas, obscuras e essenciais (FOUCAULT, 1982, p. 03).

É no contexto do dispositivo da sexualidade que a idéia de homossexualidade é produzida historicamente. Segundo Foucault, "foi por volta de 1870 que os psiquiatras começaram a constituí-la (a homossexualidade) como objeto de análise médica: ponto de partida, certamente, de toda uma série de intervenções e de 
controles novos" (FOUCAULT, 1996, p. 233). Paralelamente ao crescente interesse do discurso médico sobre a homossexualidade, surgiram também manifestações homossexuais interessadas em expor sua realidade, a verdade a partir do seu ponto de vista. Os homossexuais percebem esta dissecação de seus desejos como um desafio, produzindo como resistência outros discursos sobre si mesmos, principalmente através da literatura. Esta resistência, para Foucault, é essencial para que os movimentos homossexuais se afirmem, mas de outra forma que não aquela institucionalizada pelo dispositivo da sexualidade:

[...] está certo, nós somos o que vocês dizem, por natureza, perversão ou doença, como quiserem. E, se somos assim, sejamos assim e se vocês quiserem saber o que somos, nós mesmos diremos, melhor que vocês. Toda uma literatura da homossexualidade, muito diferente das narrativas libertinas, aparece no final do século XIX: veja Wilde ou Gide. É a inversão estratégica de uma "mesma" vontade de verdade. (FOUCAULT, 1996, p. 233)

Percebe-se então que Foucault está interessado em formas de resistência contra aquilo que é dito como verdadeiro pelos saberes legitimados em nossa sociedade. É a "inversão" do discurso, da vontade de saber, no qual os indivíduos partem de um mesmo ponto, mas chegam a lugares distintos. O autor não ignora a repressão que pode vir a ocorrer contra estes pontos de resistência, pois o poder, sendo fluido e descentralizado, surge de todos os lugares tentando capturar aqueles pontos de fuga. Se o corpo e a sexualidade revoltam-se a partir de sua própria exposição, intensificando os dizeres sobre o sexo e saturando a sociedade com uma sexualidade desmedida, o poder ressurge e torna a adequar esta resistência aos seus discursos, ou como afirma Foucault:

A revolta do corpo sexual é o contra-efeito desta ofensiva. Como é que o poder responde? Através de uma exploração econômica (e talvez ideológica) da erotização, desde os produtos para bronzear até os filmes pornográficos... Como resposta à revolta do corpo, encontramos um novo investimento que não tem mais a forma de controle-repressão, mas de controle-estimulação: "Fique nu... mas seja magro, bonito, bronzeado!" (FOUCAULT, 1996, p. 233)

Assim, o discurso da liberação sexual, da revolta contra a repressão é transformado em mercado, passa-se a consumir aquilo que um dia foi "rebelde" "alternativo"; os pontos de fuga são transformados em mercadoria e consumidos como a "última moda".

Não se pode negar que o espaço que vem sendo aberto na sociedade, principalmente pela mídia, fez com que aumentasse a discussão acerca do tema, mas até que ponto esta discussão, que poderia ter um caráter inovador e transformador, não serve aos ideais de uma sociedade normatizadora? Como aponta Louro (2001, p. 542), essa maior visibilidade: 
[...] tem efeitos contraditórios: por um lado, alguns setores sociais passam a demonstrar uma crescente aceitação da pluralidade sexual, e até mesmo, passam a consumir alguns de seus produtos culturais; por outro lado, setores tradicionais renovam (e recrudescem) seus ataques, realizando campanhas de retomada dos valores tradicionais da família até manifestações de extrema agressão e violência física.

Tem-se então o ponto de partida para a reflexão sobre os apontamentos de Foucault em relação aos movimentos homossexuais de liberação e de afirmação. Segundo ele, caberia a estes movimentos lutar por algo que supere o sexual, fugindo assim das imposições realizadas pelo dispositivo da sexualidade e pela sociedade capitalista, que estimula o consumo de produtos ligados a uma sexualidade que cultua o falo e o orgasmo. Deve-se transcender a reivindicação pela "especificidade sexual", deslocando-se "para reivindicar formas de cultura, de discurso, de linguagem etc., que são não mais esta espécie de determinação e de fixação a seu sexo" (FOUCAULT, 1996, p. 268). Mais ainda, segundo o autor, esta superação não vem ocorrendo, pois

[...] os movimentos homossexuais continuam muito presos à reivindicação dos direitos de sua sexualidade, à dimensão do sexológico. Mas isso é normal, pois a homossexualidade é uma prática sexual que, enquanto tal, é combatida, barrada, desqualificada. (FOUCAULT, 1996, p. 268)

Talvez como ponto fundamental para a discussão sobre os movimentos homossexuais organizados esteja a questão da identidade homossexual. Uma inquietação colocada por Foucault em uma de suas entrevistas relaciona-se com o problema central da homossexualidade, que segundo ele não deveria ser: "Quem sou eu? Qual o segredo do meu desejo?", mas sim: "Quais relações podem ser estabelecidas, inventadas, multiplicadas, moduladas através da homossexualidade?" (FOUCAULT, 2005, p. 1). Fica clara a sua preocupação em inventar um modo de vida que supere as questões sexuais, bem como o caráter fluído que, para ele, uma identidade deveria apresentar.

Neste sentido, Britzman (1996) aponta a importância de uma concepção não-linear entre sexo biológico, gênero e identidade sexual. Para a autora há uma presença marcante no discurso de uma confusão entre esses conceitos, o que faz com que $\mathrm{o}$ ato de quebrar essa linearidade seja visto como transgressão. $\mathrm{O}$ conceito de gênero, introduzido pelas feministas de língua inglesa nos anos 1970, visa, justamente, distinguir-se de qualquer determinação biológica, sendo o conjunto de representações construídas social e culturalmente acerca das formas de ser homem ou ser mulher em uma determinada cultura. Para Louro, a importância do conceito de gênero se afirma pois:

[...] obriga aquelas/es que o empregam a levar em consideração as distintas sociedades e os distintos momentos históricos de que estão tratando. Afasta-se (ou se tem a intenção de afastar) proposições essencialistas sobre os gêneros; a ótica está 
dirigida para um processo, para uma construção, e não para algo que exista a priori (LOURO, 1997, p. 23).

No entanto, Butler (2003, p. 25), analisando as relações de poder presentes no discurso que produz mesmo a categoria de gênero, nos alerta ainda que:

O gênero não deve ser meramente concebido como a inscrição cultural de significado num sexo previamente dado (uma concepção jurídica); tem de designar também o aparato mesmo de produção mediante o qual os próprios sexos são estabelecidos. Resulta daí que o gênero não está para a cultura como o sexo para a natureza; ele também é o meio discursivo/cultural pelo que "a natureza sexuada" ou ainda "um sexo natural" é produzido e estabelecido como "prédiscursivo", anterior à cultura, uma superfície politicamente neutra sobre a qual age a cultura [...] Na conjuntura atual, já está claro que colocar a dualidade do sexo num domínio pré-discursivo é uma das maneiras pelas quais a estabilidade interna e a estrutura binária do sexo são eficazmente asseguradas.

Britzman (1996, p. 73) enfatiza o mesmo cuidado ao afirmar que:

[...] quando se trata de questões de desejos, de amor e de afetividade a identidade é capaz de surpreender a si mesma: de criar formas de sociabilidade, de política e de identificação que desvinculem o eu dos discursos dominantes da biologia, da natureza e da normalidade.

Assim, não caberia mesmo à homossexualidade, ao se desvencilhar das categorias determinantes da biologia, buscar uma identidade delimitadora de práticas, características próprias e imutáveis, mas estar em busca do devir, do ser homossexual enquanto um modo de vida. Não se deve lutar por uma decifração e conseqüente delimitação de uma identidade homossexual, pois corre-se o risco de cair nas armadilhas da norma - estabelecendo-se como o fez anteriormente, a justiça ou a medicina - características próprias e determinantes do "desvio". Para Louro (2001, p. 544):

O discurso político e teórico que produz a representação "positiva" da homossexualidade também exerce, é claro, um efeito regulador e disciplinador. Ao afirmar uma posição-desujeito, supõe, necessariamente, o estabelecimento de seus contornos, seus limites, suas possibilidades e restrições. Nesse discurso, é a escolha do objeto amoroso que define a identidade sexual e, sendo assim, a identidade gay ou lésbica assenta-se na preferência em manter relações sexuais com alguém do mesmo sexo.

Ou seja, para a autora a preferência por determinado objeto amoroso não é a condição determinante para que um sujeito se identifique com determinada identidade sexual. A manutenção dessa noção de identidade corrobora com a tradição 
que impera em nossa sociedade, uma tradição que opera a partir do binarismo hetero/homossexual (dentre outros, como homem/mulher, feminino/masculino). Louro (2001) afirma que essa oposição está presente tanto nos discursos homofóbicos quanto naqueles que são favoráveis à homossexualidade. Segundo ela, esses discursos não escapam à referência da heterossexualidade como norma, ou seja, o tempo todo está se comparando a homossexualidade com outra coisa, que dentro de uma concepção pós-estruturalista, estaria colocada como seu oposto superior. Essa oposição cria então a figura do "outro", que, estando distante do "eu", serve de ponto de referência, de limite:

\begin{abstract}
A afirmação da identidade implica sempre a demarcação e a negação do seu oposto, que é constituído como sua diferença. Esse "outro" permanece, contudo, indispensável. A identidade negada é constitutiva do sujeito, fornece-lhe o limite e a coerência e, ao mesmo tempo, assombra-o com a instabilidade. Numa ótica desconstrutiva, seria demonstrada a mútua implicação/constituição dos opostos e se passaria a questionar os processos pelos quais uma forma de sexualidade (a heterossexualidade) acabou por se tornar a norma, ou, mais do que isso, passou a ser concebida como "natural". (LOURO, 2001, p. 549)
\end{abstract}

Em seus estudos sobre o homoerotismo, o psicanalista Jurandir Freire Costa (1992) vai ainda mais longe ao propor a substituição dos termos homossexualismo e homossexualidade pelo termo homoerotismo. Longe de ser mero jogo de palavras, para o autor as categorias que criam as identidades sexuais não são universais, mas efeitos histórico-culturais também produzidos pela linguagem. Uma dessas estratégias é designar o sujeito por determinadas parte do seu ser, transformando o que é adjetivo em substantivo, as relações particulares da vida privada, o estar homossexual, em uma categoria identitária que passa a abranger todo o sujeito. Resistir a tais terminologias implica em resistir também à carga negativa com que a ciência e a cultura vêm sobrecarregando tais termos:

Continuar discutindo sobre "homossexualidade", partindo da
premissa de que todos somos "por natureza heterossexuais,
bissexuais e homossexuais", significa tornar-se cúmplice de
um jogo de linguagem que mostrou-se violento, discriminador,
preconceituoso e intolerante, pois levou-nos a crer que pessoas
humanas como nós são "moralmente inferiores" só pelo fato
de sentirem atração por outras do mesmo sexo biológico.
(COSTA, 1994, p. 121)

Uma discussão interessante, comentada por Trevisan (1986) e Pollak (1986), refere-se justamente à questão do "ser ou estar" homossexual. Segundo Trevisan, alguns grupos organizados da década de 1980 eram contrários a uma determinação da homossexualidade enquanto condição inata, defendendo seu aspecto de circunstância. Esta visão certamente amplia as reflexões acerca de uma identidade homossexual, passando a enxergar uma disposição, um desejo sexual que pode 
variar quanto ao "objeto". Desta forma, poder-se-ia pensar em uma sexualidade menos institucionalizada.

Porém, não se pode deixar de ver o outro lado dessa discussão, pois ao se repensar a questão da identidade homossexual, derrubando as cercas da sexualidade e ampliando a percepção do desejo, pode-se retornar a uma postura opressora, que através do discurso da diversidade e do fim das identidades, passaria a ocultar a homossexualidade, encobrindo-a sob o manto da inclusão e da diversidade. Logo, não se trata de ignorar a homossexualidade, mas de ampliar a reflexão acerca das possibilidades de construção das identidades.

Pollak (1986, p. 58) pode contribuir com esta discussão ao afirmar que "não se nasce homossexual", mas que se aprende a sê-lo em decorrência das descobertas efetivadas no decorrer de sua vida. Pode-se compreender esta afirmação no sentido de que a homossexualidade deve ser de certa forma aprendida, pois sua vivência exige uma série de condutas e códigos que são modificados com o decorrer do tempo e de acordo com o local, da mesma forma que acontece com a heterossexualidade. Esta aprendizagem pode ocorrer de forma harmônica - muito difícil, em virtude da sociedade em que vivemos - ou de forma conflituosa. Pois, assim como ser homem ou mulher exige atitudes muitas vezes impostas e não aceitas sem resistência, desejar outra pessoa do mesmo sexo biológico exige uma série de atitudes pré-formatadas, de maneira explícita ou não, em uma sociedade como a nossa. Neste sentido Britzman $(1996$, p. 74) aponta a importância de se considerar as identidades como construções sociais e que, portanto, vão além de uma essência, impossibilitando assim a delimitação precisa de uma identidade e de suas características próprias:

[...] toda identidade sexual é um constructo instável, mutável e volátil, uma relação social contraditória e não-finalizada. Como uma relação social no interior do eu e como uma relação social entre "outros" seres, a identidade sexual está sendo constantemente rearranjada, desestabilizada e desfeita pelas complexidades da experiência vivida, pela cultura popular, pelo conhecimento escolar e pelas múltiplas e mutáveis histórias de marcadores sociais como gênero, raça, geração, nacionalidade, aparência física e estilo popular.

Para Foucault, a jornada não deve buscar descobrir "quem se é", "como se é" ou "por que se é" de determinada maneira, mas sim como fazer da vida uma experiência transformadora e renovada a cada experiência, libertando-se de valores morais socialmente impostos e regulados, nas suas palavras: "temos que nos esforçar em nos tornar homossexuais e não nos obstinarmos em reconhecer que o somos" (FOUCAULT, 2005, p. 1).

Outro ponto levantado pelo autor refere-se à imagem construída ao redor da homossexualidade, imagem esta que deve ser combatida, mesmo que às custas da resistência daqueles que não a aceitam enquanto existência válida. Na sua opinião, a homossexualidade deixa-se ver apenas como uma "forma de um prazer imediato", uma vez que o que choca as pessoas, não seria o ato sexual em si, mas 
a possibilidade "que indivíduos comecem a se amar, e aí está o problema" (FOUCAULT, 2005, p. 1).

Percebe-se claramente esta disposição da opinião pública em geral em considerar a homossexualidade enquanto uma prática estritamente sexual, que excluiria quaisquer outros sentimentos que seriam próprios apenas dos relacionamentos heterossexuais, visto que como afirma Foucault: "continuamos a pensar que algumas dentre elas [práticas que transgridem a lei] insultam a 'verdade': um homem 'passivo', uma mulher 'viril', pessoas do mesmo sexo que se amam [...]" (FOUCAULT, 1982, p. 3). Ainda em relação à imagem dominante relacionada às homossexualidades, tem-se o que Britzman chama de mitos, que são utilizados como forma de garantir a permanência da heteronormatividade “... isto é, a obsessão com a sexualidade normalizante, através de discursos que descrevem a situação homossexual como desviante" (BRITZMAN, 1996, p. 79). Segundo a autora o primeiro mito relaciona-se com a aceitação da heterossexualidade como "normal" e "natural", vinculando-se à idéia de que informações sobre e vivências com pessoas homossexuais poderia "contagiar" os heterossexuais. O segundo mito assume que os/as jovens não têm maturidade para assumir sua homossexualidade, sendo, portanto, ainda passíveis de "regeneração". E o terceiro mito pressupõe que as identidades sexuais são construídas de forma privada e particular, "impedindo que concebamos a sexualidade como sendo definida no espaço social mais amplo, através de categorias e fronteiras sociais. A sexualidade não é constituída apenas de um conjunto de ações individuais específicas" (BRITZMAN, 1996, p. 80).

Foucault aponta alternativas para a construção de um "modo de vida homossexual", estando a principal delas centrada na amizade alcançada através de uma ascese individual (não no sentido de renúncia, mas no sentido de um cuidado de si) e de uma dessexualização das relações (também não no sentido de uma repressão do sexual, mas no sentido de uma desconstrução do modelo fálico da sexualidade). Em seu livro Amizade e estética da existência em Foucault (1999), Francisco Ortega visa discutir algumas destas questões referentes à amizade enquanto possibilidade de reconstrução de uma estética da existência e de um modo de vida homossexual, idéia presente nos últimos trabalhos de Foucault.

A primeira questão levantada por Ortega refere-se à dessexualização do prazer, buscando-se novas formas que superem o ato sexual - penetração - com objetivo único de alcançar o orgasmo. Forma esta institucionalizada em nossa sociedade que, a partir do dispositivo da sexualidade, criou uma scientia sexualis em detrimento de uma ars erótica. Segundo Ortega (1999, p. 147), "as práticas sadomasoquistas constituem, para Foucault, uma forma de dessexualizar o prazer, criando novas possibilidades de obter prazer". Estas práticas seriam, dentro da opção de Foucault, uma alternativa para os valores institucionalizados em nossa sociedade, valores que dicotomizam, por exemplo, prazer e dor. Esta seria uma das formas de buscar prazer através de diversas partes do corpo, através de diversos tipos de instrumentos e sensações contra o dispositivo da sexualidade (ORTEGA, 1999, p. 148). 
Com relação à amizade, Ortega (1999, p. 154) afirma que Foucault a via como uma forma de "atualização da estética da existência", destinando-se à cultura homossexual. Esta retomada da estética da existência através da amizade seria, segundo Ortega (1999, p. 156), possibilitada pela forma de vida atual, na qual "os conceitos que organizavam a dinâmica da sociedade industrial: classe, família, profissão, matrimônio, sexualidade" estariam superados por novas formas de organização. Assim, abre-se espaço para novas formas de vida, novas construções sociais e subjetivas, sendo que a homossexualidade ocupa um lugar importante, uma vez que se organiza dentro de relações diferenciadas das impostas à heterossexualidade.

A amizade colocada por Foucault se distingue daquela presente na Antiguidade, pois aquela se tratava de uma forma institucionalizada e sem espaço para a experimentação (ORTEGA, 1999, p. 160). Outra diferença fundamental refere-se à separação que lhe era imposta naquele contexto em relação ao eros e à philia. Para Foucault interessava aproximar estes dois componentes, tornando a amizade uma busca mútua por prazer, porém não implicando necessariamente "que toda amizade deva ter um caráter sexual” (ORTEGA, 1999, p. 161).

Sobre a ascese, enquanto prática que leva à uma nova forma de vida homossexual, Ortega (1999, p. 166) afirma que:

\begin{abstract}
A ascese é a tarefa de auto-elaboração. Na discussão atual sobre a amizade, a ascese deve desempenhar uma função importante, pois mediante as práticas de si pode-se alcançar uma ascese homossexual, que permita inventar um modo de vida até agora improvável. As decisões sexuais possuem uma dimensão existencial, atravessam a totalidade da vida e são susceptíveis de transformá-la [...] Ser homossexual significa para Foucault ser em devir.
\end{abstract}

Assim, para Foucault, caberia a cada indivíduo tomar as decisões acerca de suas práticas, sexuais ou não. Este trabalho constituiria, então, a identidade de cada um, não somente enquanto identidade sexual, mas a partir da busca de novas formas de existência e de vivência dos prazeres, independentemente das regras sociais e sexuais impostas pela sociedade e pelo dispositivo da sexualidade. Ainda neste sentido, Ortega (1999, p. 167) afirma que "cada indivíduo deve formar sua própria ética; a ética da amizade prepara o caminho para a criação de formas de vida, sem prescrever um modo de existência como correto"; em que a amizade joga dentro das relações de poder, não permitindo que elas se transformem em "estados de dominação" (ORTEGA, 1999, p. 168).

Dentro desta concepção de modo de vida homossexual, não caberia a luta dos homossexuais por direitos iguais aos dos heterossexuais, pois segundo Ortega (1999, p. 169), "isto significaria a ampliação a círculos homossexuais das formas de comunidade e relacionamento reduzidas na atualidade aos heterossexuais, em vez de inventar novas formas de existência não institucionalizáveis". Ou seja, lutar pelo direito de ter as mesmas formas de vida e de relacionamento que têm os heterossexuais significa institucionalizar e limitar uma forma de vida que pode inventar uma 
série de possibilidades de existência, que podem ir além do casamento, da família e da monogamia imposta pelo Estado. Seria inverter o processo criativo de construção de uma ética individual e de novas formas de relacionamento.

Sendo assim:

\begin{abstract}
A luta homossexual deve (nisto consiste seu poder transgressivo ampliável a outros tipos de conflitos sociais: movimentos anti-racistas, ou feministas etc.) aspirar à criação de um novo "direito relacional", que permita todo tipo possível de relações, em vez de impedi-las ou bloqueá-las [...] A possibilidade de constituir formas novas de sociedade é também possível para a comunidade heterossexual, que tem de ser incluída na luta por um novo "direito relacional". (ORTEGA, 1999, p. 170)
\end{abstract}

Pois, segundo Foucault, um novo modo de vida pode superar as barreiras sociais e históricas colocadas entre os indivíduos, uma vez que "um modo de vida pode ser partilhado por indivíduos de idade, estatuto e atividades sociais diferentes" (FOUCAULT, 2005).

A amizade colocada pelo autor como possibilidade de relacionamento tem como uma de suas funções superar esta identidade sexualizada imposta pela sociedade, o que levaria a uma transformação deste estilo de vida homossexual voltado para a busca do orgasmo, em que "isso em que devemos trabalhar, me parece, não é tanto em liberar nossos desejos, mas em tornar a nós mesmos infinitamente mais suscetíveis a prazeres" (FOUCAULT, 2005, p. 1).

Concluímos nossa reflexão sobre os movimentos homossexuais e a questão da identidade sexual com as afirmações feitas por Mac Rae (1987). O autor questiona a validade dessas lutas, uma vez que estas privilegiariam a imposição de uma identidade homossexual, chegando-se a ponto da criação de guetos que rejeitam a participação de "outros". Considerando-se a identidade sexual uma construção individual e social, exigir uma homossexualidade essencial ou intrínseca ao indivíduo constitui-se como uma contradição. Ao mesmo tempo em que eles lutam pelo fim do preconceito acabam tornando-se rígidos na exigência de um "padrão" homossexual.

Isso levaria a uma regulamentação das práticas, um controle sobre os indivíduos e uma padronização que tornaria mais aceito aquele homossexual que se encaixa em um modo de ser específico. Isso fecha um círculo no qual ficam de fora aqueles que mais "incomodam" e que não se encaixam nesse padrão. Deve-se então partir desses discursos moralizantes para uma resistência criativa, inventando novas formas de ser e fugindo dessas limitações impostas por uma identidade fixa. Não ficar preso em guetos, nos quais se localizam "nós" e "eles", e sim criar novas formas de vida que reconheçam a multiplicidade de prazeres e desejos, bem como as diversas formas de ser homem e mulher.

Sabemos que, ao questionar a luta pela união civil ou pela garantia dos direitos sociais aos quais não têm direitos os/as homossexuais, estamos talvez nos 
antecipando a uma luta que ainda não pode ser travada; afinal a homossexualidade, antes de buscar a construção de novas formas de existência, precisa ultrapassar barreiras mais arcaicas como a impossibilidade de constituição de uma família de direito diante da sociedade. Concordamos com os/as autores/as quando afirmam que se deveria lutar pela derrubada dos atuais padrões sociais - família nuclear, burocratização das relações, casamentos presos a cerimônias tradicionais etc. - e não simplesmente pela inserção da diversidade nesses padrões. Mas antes disso precisamos também reconhecer que enquanto os/as homossexuais não tiverem acesso a direitos civis, como adoção de crianças, e à "legalização" de suas uniões, por exemplo, nada poderá ser feito, a não ser que toda a sociedade civil, sem distinção, lute de forma conjunta para a transformação desses valores. Enquanto isso não ocorrer, cada um tem o direito de viver de acordo com aquilo que the garante o sentimento de inserção na sociedade, e isso deve ser garantido.

Desta forma, esperamos colaborar com uma discussão que vá além da mera luta pela união civil e/ou religiosa, e pela garantia de direitos que nos são impostos como necessários e corretos. Buscamos dar um passo além, mesmo que de forma inicial e teórica, para que todos/as possam recriar novas formas de existência.

\section{REFERÊNCIAS}

BRITZMAN, D. O que é esta coisa chamada amor - identidade homossexual, educação e currículo. Revista Educação e Realidade, Porto Alegre, v. 21, n. 1, p. 71-96, jan./jun. 1996.

BUTLER, J. Problemas de gênero: feminismo e subversão da identidade. Rio de Janeiro: Civilização Brasileira, 2003.

COSTA, J. F. A ética e o espelho da cultura. Rio de Janeiro: Rocco, 1994.

. A inocência e o vício: estudos sobre o homoerotismo. Rio de Janeiro: Relume-Dumará, 1992.

FOUCAULT, M. Da amizade como modo de vida. De l'amitié comme mode de vie. Entrevista de Michel Foucault a R. de Ceccaty, J. Danet e J. le Bitoux. Tradução: Wanderson Flor do Nascimento. Gai Pied, [S.1.], n. 25, p. 38-39, abr. 1981. Disponível em: $<$ http://www.unb.br/fe/tef/filoesco/foucault/amitie.html $>$. Acesso em: 22 abr. 2005.

. Herculine Barbin: o diário de um hermafrodita. Rio de Janeiro: F. Alves, 1982.

Microfisica do poder. Rio de Janeiro: Graal, 1996.

LOURO, G. L. Gênero, sexualidade e educação: uma perspectiva pós-estruturalista. Petrópolis: Vozes, 1997. 
. Teoria queer: uma política pós-identitária para a educação. Revista Estudos Feministas, Florianópolis, v. 9, n. 2, p. 541-553, 2001.

MAC RAE, E. Afirmação da identidade homossexual: seus perigos e sua importância. In: TRONCA, Í. (Org.). Foucault vivo. Campinas, SP: Pontes, 1987.

ORTEGA, F. Amizade e estética da existência em Foucault. Rio de Janeiro: Graal, 1999.

POLLAK, M. A homossexualidade masculina, ou: a felicidade no gueto? In: ARIÉS, P.; BÉJIN, A. (Org.). Sexualidades ocidentais. São Paulo: Brasiliense, 1986.

TREVISAN, S. J. Devassos no paraíso. Rio de Janeiro: M. Limonad, 1986.

Recebido em: março de 2006

Aceito em: agosto de 2006 